\title{
Study Of Modified Wood As A Bearing Material For Machine-Building
}

\author{
Vladimir Shamaev \\ Voronezh state university of forestry and technologies \\ named after G.F. Morozov \\ Voronezh, Voronezh region, Russian Federation \\ e-mail: drevstal@mail.ru
}

\author{
Ilya Medvedev \\ Voronezh state university of forestry and technologies \\ named after G.F. Morozov \\ Voronezh, Voronezh region, Russian Federation \\ e-mail: medved-vrn82@mail.ru
}

\author{
Dmitry Parinov \\ Voronezh state university of forestry and technologies named after G.F. Morozov Voronezh, Voronezh region, Russian \\ Federation \\ e-mail: dmitryparinov@mail.ru
}

\begin{abstract}
Modified wood is used in the form of sliding bearings in friction units of various machines and mechanisms, mainly operating under severe operating conditions (combines, rock loading machines, belt conveyors). Wide use of such bearings is constrained by low thermal conductivity of wood. Technology and equipment for metallization of wood with tetracarbonyl pairs $\mathrm{Ni}(\mathrm{CO})_{4}$ have been developed to increase thermal conductivity of modified wood, when metallic nickel is deposited as a continuous film with a thickness of $0.4 \mu \mathrm{m}$. As a result, thermal conductivity of wood increases from 0.4 $\mathrm{W} / \mathrm{m} /$ degree to $10-15 \mathrm{~W} / \mathrm{m} /$ degree with a nickel content of $2-5 \%$ by weight of wood. Use of bearings made of metalized wood is possible at a temperature of $120^{\circ} \mathrm{C}$ in the friction zone, instead of $80^{\circ} \mathrm{C}$ - for conventional pressed wood.
\end{abstract}

Keywords-wood; metallization; modification; thermal conductivityg

\section{INTRODUCTION}

Modified wood (MD), production volume of which has reached 200 thousand $\mathrm{m}^{3}$ in the world, is used mainly as a substitute for valuable hardwoods and only about $1 \%$ as a material for friction units [1-4]. Studies on obtaining bearings from MD have been conducted in Russia, Belarus, the US and China [5, 6]. To increase wear resistance of $M D$, it is strengthened by pressing to a density of $1200 \mathrm{~kg} / \mathrm{m}^{3}$, nanocrystalline cellulose is introduced into the wood $[7,8]$. To reduce the coefficient of friction, wood is filled with various lubricants, most often with Biol lubricant containing nanografite and molybdenum disulphide [9, 10]. Bearings from MD are used instead of bronze, babbits, textolite and plastics ones.

Many attempts have been made to increase thermal conductivity of wood, because wooden bearings do not practically remove heat from the friction zone and are charred before they wear out. There are few publications on these studies, because the results were negative, but mention of them is very productive. Experiments for increasing thermal conductivity of wood have been carried out in the following areas:

a) Introduction of molten low-melting metals into wood with a melting point of $80-140^{\circ} \mathrm{C}$.

b) Impregnation of wood with metal salts followed by isolation of metal by electrolysis.

c) Impregnation of wood with metal salts, most often copper with decomposition of salt to oxide and reduction of metal from oxide by hydrogen.

d) Impregnation of wood with strong flame retardants and subsequent impregnation with molten metals with a melting point of $200-300^{\circ} \mathrm{C}$.

Impregnation of wood with liquid alloys of tin, lead and bismuth gave an increase in thermal conductivity from 0.5 $\mathrm{W} / \mathrm{m} /$ degree to $5-7 \mathrm{~W} / \mathrm{m} /$ degree, but metal content was 30 $50 \%$ by volume and $300-500 \%$ by weight from the corresponding volume and mass of dry wood [11]. With a smaller metal content, the discreteness of the metal column in the capillaries appeared and thermal conductivity disappeared. Variants $b$ and $c$ gave the metal in the form of a powder that does not have thermal conductivity. Variant $d$ led to instantaneous combustion of samples.

New possibilities have arisen in connection with the production of metals from carbonyls in the form of a continuous film with a thickness of $0.4 \mu \mathrm{m}$ on a nonmetallic substrate [12]. This method has been successfully applied to increase thermal conductivity of wood [13].

\section{EXPERIMENTAL PROCEDURE}

Installation of metallization of wood takes place with nickel tetracarbonyl vapors. The essence of this method consists in thermal dissociation of nickel tetracarbonyl (NTC) vapor on the inner surface of wood vessels to form a metallic nickel film.

The deposited metal is evenly distributed inside the wood, ensuring a sufficiently reliable contact with it. 
The basic technological scheme of the unit for wood modification is presented in Fig.1; a general view is shown in Fig. 2.

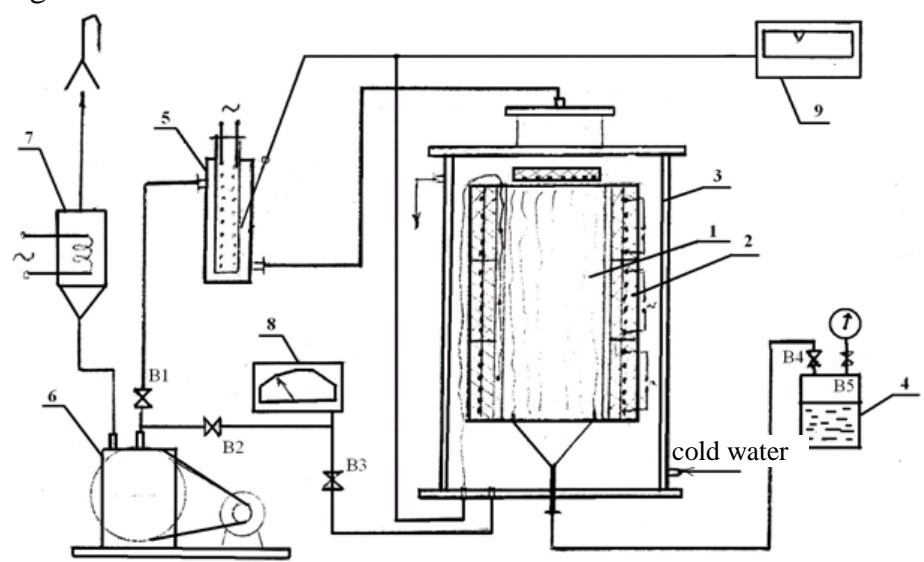

1 - blank; 2 - sectional heater; 3 - metallization apparatus (reactor); 4 - nickel tetracarbonyl evaporator (NTC); 5 - furnace for decomposition of NTC vapors; 6 - vacuum pump; 7 - carbon dioxide burning furnace; 8 - vacuum gauge;

9 - potentiometer

Fig.1. Technological scheme of the process of wood modification with nickel tetracarbonyl (NTC)

Wood modification is carried out as follows. Wood blank 1 , previously dried to constant weight to avoid inhibition by the moisture at the metal deposition process, is placed inside sectional heater 2 located vertically in reactor 3 . At the same time, the bottom of the blank is hermetically connected to nickel tetracarbonyl evaporator 4. The apparatus is closed and evacuated with vacuum pump 6. Pumping out of the apparatus is carried out continuously from the side opposite to the supply of carbonyl vapor.

Thereafter, all sections of the heater are turned on and the temperature in them is adjusted to $20-30{ }^{\circ} \mathrm{C}$ before vapors decomposition of the used nickel tetracarbonyl starts and kept at this temperature for 10-15 minutes until the entire volume of the wood blank is uniformly warmed up. Then, temperature of the upper section of the heater is increased to the value when decomposition of nickel tetracarbonyl vapor starts and after heating a sample is fed with nickel tetracarbonyl vapors from the lower part of the blank with a speed of no more than $20 \mathrm{l} / \mathrm{h}$. After that, successively from the top to down, the following sections of the heater are switched on, ensuring the movement of the thermal zone at a speed of no more than 2.5 $\mathrm{mm} / \mathrm{min}$.

With the aim of destroying undesirable vapors of nickel tetracarbonyl and carbon oxide, evolved in the process, the furnace is provided in the scheme (5) and (7) respectively.

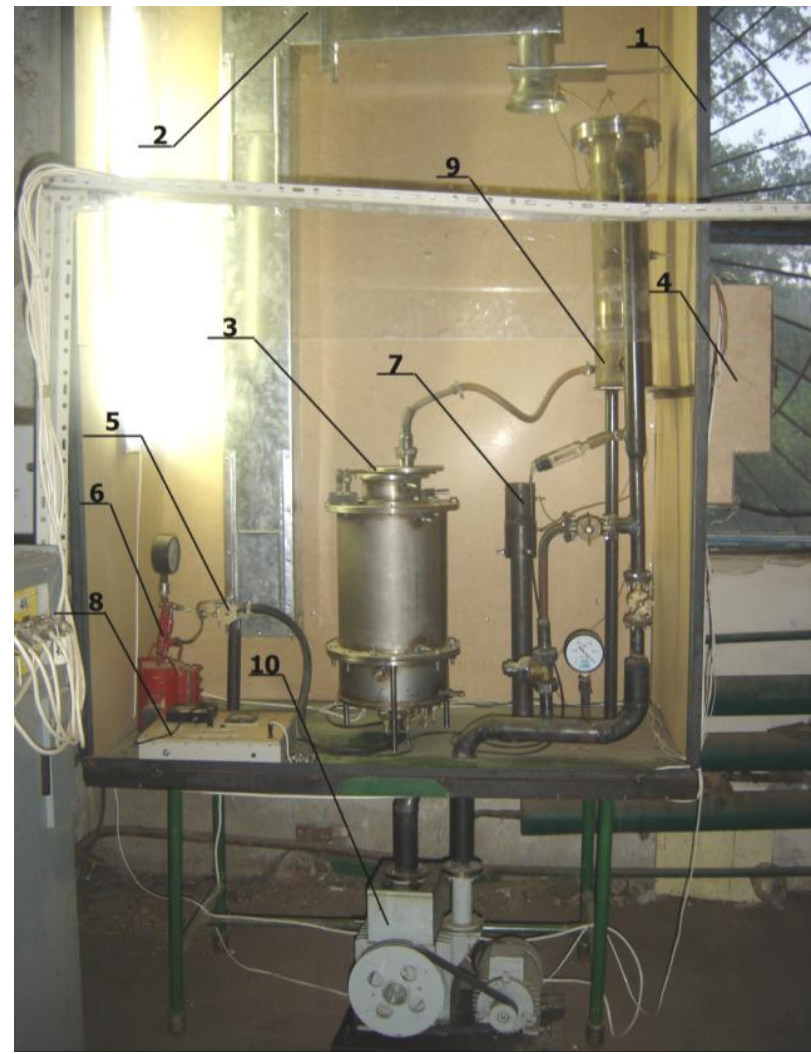

1 - fume hood; 2 - ventilation system; 3 - reactor; 4 control panel; 5 - batcher; 6 - cylinder with nickel tetracarbonyl; 7 carbon monoxide burning furnace; 8 - thermocouple vacuum gage WT-1; 9 - furnace for decomposition of nickel tetracarbonyl; 10 vacuum pump

Fig. 2 A general view of the unit for wood modification with nickel tetracarbonyl vapors

\section{III.DISCUSSION OF THE RESULTS}

A uniform formation of the metal film along the entire length occurs with thermal dissociation of nickel tetracarbonyl vapors, when they are forced through wood through the internal surface of the vessels, Fig. 3.

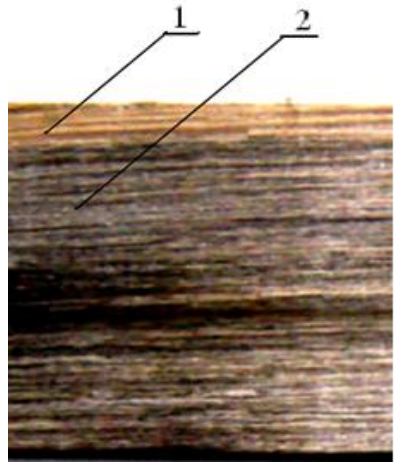

Fig. 3 A sample of birch wood after a process of impregnation with vapors of nickel tetracarbonyl (powered x 200, radial cut): 1-fibers of wood coated with nickel; 2-pure wood fibers

To improve thermophysical properties of pressed wood, a technology has been developed for thermal dissociation of 
highly volatile organometallic compounds (OMC) when they are forcedly pumped through the inner part of the blank in order to obtain uniformly distributed metallic films on the inner surface of vessels and capillaries. And the consequence of this process is an increase in the coefficient of thermal conductivity of wood.

This process is carried out in a shallow vacuum by thermal dissociation of metal carbonyl vapor on the inner surface of heated vessels and wood capillaries. The above process is described by equation:

$$
\begin{gathered}
\mathrm{Me}_{n}(\mathrm{CO})_{m} \rightarrow n \mathrm{Me}+m \mathrm{CO} \\
m \mathrm{CO}+\mathrm{O}_{n} \rightarrow m \mathrm{CO}
\end{gathered}
$$

where $M e$ - metal which forms part of a chemical compound; $\mathrm{CO}$ - carbon monoxide; $n$ and $m$ - coefficients

The metal is introduced by thermal dissociation of highly volatile OMCs by forced pumping of their vapors through the wood with a counter-motion of the thermal zone with a temperature sufficient for OMC vapor decomposition, but not exceeding the temperature of wood destruction. In this case, wood, used for this process, is dried to constant weight. Nickel tetracarbonyl (NTC) is used as initial MOC. Deposited metal in the form of thin films of nickel is evenly distributed on the inner surface of vessels and wood capillaries, providing sufficiently reliable contact with it.

As a result of thermal dissociation of wood in NTC vapors and its subsequent pressing, a significant increase in thermal conductivity of the resulting material in comparison with the initial one occurs. The coefficient of thermal conductivity of such pressed wood along the fibers with a density of 1200 $\mathrm{kg} / \mathrm{m}^{3}$ depends on the amount of deposited metal on the inner walls of vessels and capillaries.

\section{METHODS FOR STUDYING THE THERMAL PROPERTIES OF WOOD}

To perform analytical calculations of the distribution of temperature fields in nonstationary heat exchange, it is necessary to determine experimentally the thermophysical properties and, in particular, thermal conductivity of wood impregnated with nickel tetracarbonyl.

The analytical ways of determining the temperature field for nonstationary heat exchange are based on solving a partial differential equation for the convective heat transfer. For this, it is necessary to have exact values of thermophysical constants characterizing the intensity of heat exchange on the surface with the surrounding medium and the total heat capacities of natural wood and impregnated with sodium chloride. The total heat capacity of two materials is understood as the ratio of their thickness, heat conductivity and specific heat.

For wood impregnated with tetra carbonyl nickel, their numerical value must be determined experimentally.

The analysis of modern methods of determining the coefficient of thermal conductivity shows that, despite the considerable number of developed methods, it is difficult to choose a method that corresponds to the specificity of the formation of temperature field in the wood. The most suitable method for studying thermal conductivity of thin-layer materials in the nonstationary regime is the so-called method of two temperature-time intervals. A small-scale modernization of the method makes it much easier.

Fig.4 shows a scheme of a two-part system with the specimen under study.

As can be seen from this figure, one of the junctions of the differential thermocouple is placed inside the heat sink, and the other - in the constant temperature heater. In this case, the indication $N_{o}$ of galvanometer included in the thermocouple circuit corresponds to the temperature difference $t_{n}-t_{0}$.

When the system comes in contact with the heat sink and the specimen in the form of a thin flame with the heater, the system temperature increases and $\mathrm{N}$ galvanometer readings decrease. Determination of the coefficient of thermal conductivity of the test specimen is reduced to two time intervals fixing: $\Delta \tau_{1}=\tau_{2}-\tau_{1}$ and $\Delta \tau_{2}=\tau_{3}-\tau_{1}$ corresponding to two given changes in the readings of the galvanometer $\Delta N_{1}=N_{1}-N_{2}$ and $\Delta N_{2}=N_{1}-N_{3}$.

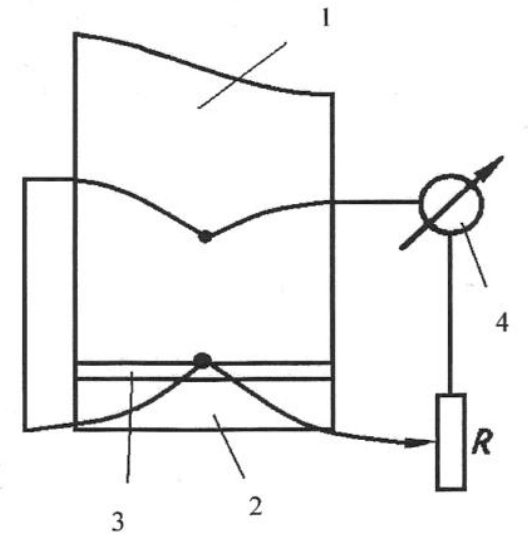

1 - heat sink; 2 - heater; 3 - specimen; 4 - galvanometer;

$$
\mathrm{R} \text { - rheostat }
$$

Fig. 4. A scheme of a two-part system for determining the coefficient of thermal conductivity of wood by the method of two temperaturetime intervals

Obtained values $\Delta \tau_{1}$ and $\Delta \tau_{2}$ enable one to find the coefficient of thermal conductivity of the test specimen from expression:

$$
\lambda=b \cdot \varepsilon \sqrt{a}=\frac{b \cdot \varepsilon \cdot h}{2 \cdot \sqrt{P \cdot \Delta \tau}}
$$

where $b$ - the constant of heat sink, which characterizes its thermal activity; $P$ and $\varepsilon$-dimensionless parameters; $h$ specimen thickness, $\mathrm{m}$.

The dimensionless parameters in (3) are found from the working tables giving the dependence of $\mathrm{P}$ and on the values found in the experiment. The dimensionless parameters in (3) are found from the working tables giving the dependence of $P$ and $\varepsilon$ on values $\Delta \tau_{1}$ and $\Delta \tau_{2}$ found in the experiment.

The change in the readings of the galvanometer with time is associated with a change in the relative temperature $\theta=\frac{t}{t_{n}}$ at point $\theta$ of the system by relation: 


$$
\frac{N}{N_{0}}=\frac{t_{H}-t}{t_{H}}=1-\Theta .
$$

Equation $\Theta=f(\tau)$ describing changes in the relative temperature $\theta$ at point $\mathrm{O}$ of the system has the form:

$$
\Theta=1+\frac{\alpha}{\operatorname{erfc}(y)-\alpha \operatorname{erfc}(3 y)+\ldots}=F(\alpha, y) .
$$

In this equation:

$$
\begin{gathered}
\alpha=\frac{\varepsilon-1}{\varepsilon+1} \\
\varepsilon=\frac{\lambda}{b \sqrt{a}} \\
b=\frac{\lambda_{T}}{\sqrt{a_{T}}} \\
y=\frac{h}{2 \sqrt{\alpha \cdot \tau}} \\
\operatorname{erfc}(y)=1-\operatorname{erf}(y) \\
\operatorname{erf}(y)=\frac{2}{\sqrt{\pi}} \int_{0}^{y-y^{2}} e
\end{gathered}
$$

where - $d y$ - the Gaussian integral; $\lambda_{\mathrm{T}}, \alpha_{\mathrm{T}}$ - coefficients of thermal conductivity and thermal diffusivity of heat sink, $\mathrm{W} /\left(\mathrm{m}^{2} \cdot{ }^{\circ} \mathrm{C}\right)$ and $\mathrm{m}^{2} / \mathrm{s}$.

When working with this technique, it is necessary to strive to increase measured time intervals $\Delta \tau_{1}$ and $\Delta \tau_{2}$, for which it is necessary to use the heat sink with a large value of constant $b$.

Nodal points can be found from dependence $\frac{\varepsilon}{y}=f(\varepsilon)$. From relation $M=\frac{\varepsilon}{y}$, it follows that $y=\frac{\varepsilon}{M}$; then for selected interval $\Delta \Theta=\Theta_{2}-\Theta_{1}$ parameter $P$ is determined from expression:

$$
P=\frac{y_{1}^{2}}{\left(\frac{y_{1}}{y_{2}}\right)^{2}-1}=\frac{\left(\frac{\varepsilon}{M}\right)^{2}}{\left(\frac{M_{2}}{M_{1}}\right)^{2}-1}
$$

whence

$$
\frac{\varepsilon}{\sqrt{P}}=\sqrt{M_{2}^{2}-M_{1}^{2}}
$$

where $\mathrm{M}_{2}$ and $\mathrm{M}_{1}$ - values of $M$ corresponding to the values of:

$$
\begin{aligned}
& \Theta_{1}=1-N_{1}-N_{0} \\
& \Theta_{2}=1-\frac{N_{2}}{N_{0}} .
\end{aligned}
$$

Hence thermal conductivity coefficient taking into account (13) takes the form:

$$
\lambda=\frac{b \cdot h}{2 \cdot \sqrt{\Delta \tau}} \cdot \sqrt{M_{2}^{2}-M_{1}^{2}} .
$$

Thus, measurement of the coefficient of thermal conductivity of specimen reduces to determination of the time interval, which corresponds to difference $\Delta \Theta=\Theta_{2}-\Theta_{1}$, where $\Theta_{1}$ and $\Theta_{2}$ - values convenient for measurement:

$$
\begin{gathered}
\Theta_{1}=1-\frac{N_{2}}{N_{1}} ; \\
\Theta_{2}=1-\frac{N_{2}}{N_{0}} .
\end{gathered}
$$

For the practical implementation of the non-stationary method for determining the thermal conductivity of wood samples, an installation has been constructed.

The installation consists of three units: a heat sink with a test sample, a heater and a measuring complex.

To create a reliable thermal contact between the specimen and the heat sink, the system has been loaded with a constant load, and a junction of the thermocouple with the lead-in conductors has been deepened into the body of the heat sink. Chromel-copel thermocouples from electrodes with a diameter of $0.3 \mathrm{~mm}$ have been used for temperature measurements.

The installation has used an electric heater with a thermostatic device, which makes it possible to create a constant temperature on the surface of the heater.

Electrical measuring circuit is made up of a differential chromel-copel thermocouple, a mill voltmeter M 830 and an automation unit.

It is possible to measure thermal conductivity of thin-layer specimens of various materials in the non-stationary regime by the method of two temperature-time intervals.

To determine the coefficient of thermal conductivity, samples with a thickness of about $1 \mathrm{~mm}$ (end sections) have been used.

The main thermo physical indices of the pressed wood containing nickel are given below in Fig.5.

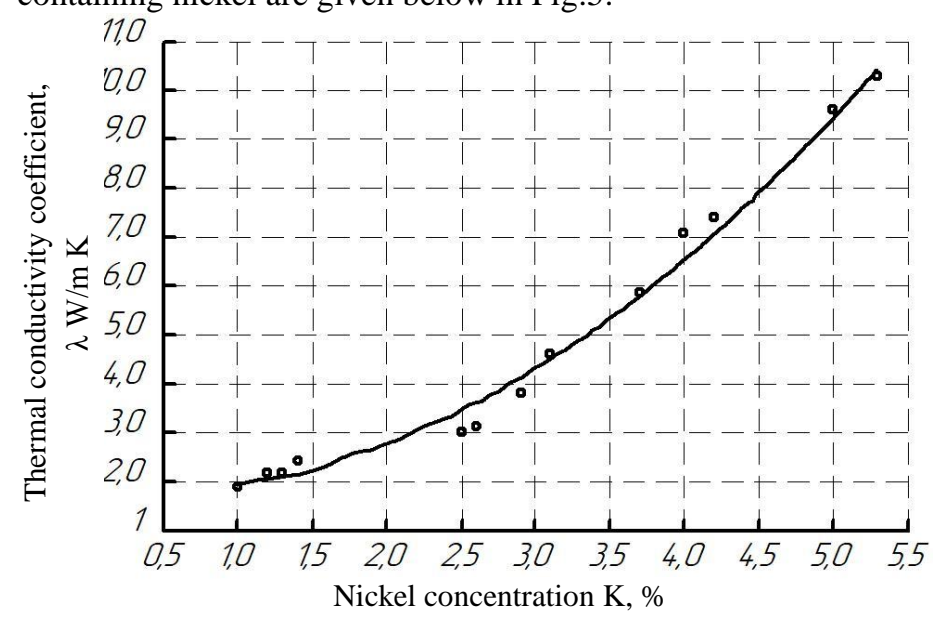

Fig. 5 Dependence of thermal conductivity of pressed wood on the metal content in the sample by weight along the fibers (when $\rho=1200 \mathrm{~kg} / \mathrm{m}^{3}$ ).

The presence of metallic nickel improves antifriction properties of modified wood.

The results of preliminary studies of specimens of modified wood containing various combinations of nickel and antifriction filler concentrations are given in Table 1. Tests have been carried out at a load of $8 \mathrm{MPa}$, sliding speed of 0.2 
$\mathrm{m} / \mathrm{s}$ and maximum content of the antifriction filler. At this test speed, the temperature in the friction zone does not rise to the melting point of the modifier, thereby creating conditions for the lowest coefficient of friction. The load of $8 \mathrm{MPa}$, although not critical for pressed wood, completely eliminates creation of thick molecular films.

TABLE 1 - COEFFICIENTS OF FRICTION AND WEAR OF PRESSED WOOD, DEPENDING ON NICKEL CONTENT AT A LOAD OF 8 MPA AND SLIDING SPEED OF $0.2 \mathrm{M} / \mathrm{S}$

\begin{tabular}{|c|c|c|c|c|}
\hline $\begin{array}{c}\text { Concentra } \\
\text { tion of } \\
\text { nickel, } K, \\
\%\end{array}$ & $\begin{array}{c}\text { Concentra } \\
\text { tion of } \\
\text { antifrictio } \\
\text { n filler, } C, \\
\%\end{array}$ & $\begin{array}{c}\text { Coefficie } \\
\text { nt of } \\
\text { friction, } f\end{array}$ & $\begin{array}{c}\text { Temperat } \\
\text { ure in the } \\
\text { friction } \\
\text { zone, } t, \\
{ }^{0} \mathrm{C}\end{array}$ & $\begin{array}{c}\text { Wear, } \\
h, \mu \mathrm{m}\end{array}$ \\
\hline 0.5 & 8.5 & 0.042 & 97 & 7.9 \\
\hline 0.8 & 8.5 & 0.042 & 95 & 8.3 \\
\hline 1.2 & 8.5 & 0.042 & 93 & 7.3 \\
\hline 1.5 & 8.5 & 0.04 & 90 & 6.7 \\
\hline 1.9 & 8.5 & 0.039 & 87 & 6.4 \\
\hline 2.1 & 8.5 & 0.038 & 73 & 5.9 \\
\hline 2.5 & 8.5 & 0.038 & 62 & 5.5 \\
\hline
\end{tabular}

Tests of sliding bearings from metalized pressed wood with Biol lubricant have showed that temperature in the friction zone can be increased from $80^{\circ} \mathrm{C}$ to $120^{\circ} \mathrm{C}$, shaft speed - from $0.5 \mathrm{~m} / \mathrm{s}$ to $5 \mathrm{~m} / \mathrm{s}$ [14]. The research materials presented in this article were obtained as a part of the state task of the Ministry of Education and Science of Russia, № 11.3960.2017/4.6.

\section{CONCLUSIONS}

1. A technique has been developed and an installation has been created that enables one to metalize wood with nickel tetracarbonyl vapors.

2. Continuous metallization of wood with nickel in the form of a film with a thickness of $0.4 \mu \mathrm{m}$, lining the entire inner surface of wood has been applied experimentally.

3. For the first time, it has been possible to increase thermal conductivity of wood 20 times with nickel content of $5 \%$ by mass and $0.8 \%$ by volume of wood.

4. The coefficient of friction of metalized wood is 0.04 , and wear is within 6-8 microns.

\section{References}

[1] S. Lekounougou, D. Kocaefe, N. Oumarou, Y.S. Kocaefe, "Poncsak Effect of thermal modification on mechanical properties of Canadian white birch (betula papyrifera)," International Wood Products Journal, 2011, Vol. 2, № 2, pp. 101-107.

[2] M.A. Tshabalala, J.D. McSweeny, R.M. Rowell "Peat treatment of wet wood fiber: a study of the effect of reaction conditions on the formation of furfurals," Wood Material Science and Engineering, 2012, Vol. 7, № 4, pp. 202-208.

[3] D. Sandberg, P. Haller, P. Navi "Thermo-hydro and thermo-hydromechanical wood processing: an opportunity for future environmentally friendly wood products," Wood Material Science and Engineering, 2013, Vol. 8, № 1, pp. 64-88
[4] R.M. Rowell, I. Andersone, B. Andersons, Heat treatment, Chapter 14 in Handbook of Wood Chemistry and Wood Composites, Second Edition, CRC Press, 2012, pp. 511-536.

[5] V.A. Shamaev, D.A. Parinov, A.N. Polilov, Investigation of sliding bearings for heavily loaded friction units - Problems of machine building and machine reliability, 2018, №1, p. 54-59.

[6] Pressed wood in mechanical engineering. Reference book, Voronezh: VSAFT, 2005, pp. 90

[7] S.A. Burlov, V.V. Postnikov, N.A. Trubnikov, O.A. Kalinina, M.N. Levin, Method for obtaining modified wood. Patent of the Russian Federation 2340443, 2008, bil. № 34

[8] N.S. Nikulina, S.A. Konstantinova, "Application of nanocrystalline cellulose in the process of gluing and modifying wood," Lesnoy Vestnik Moscow State Forest University, Moscow: Mytischi, 2012, №8 (91), pp. 107-110.

[9] V.A. Shamaev "Sliding bearings from modified wood," Bulletin of Mechanical Engineering, 2012, №7, pp. 45-49.

[10] V.A. Beliy, V.I. Vrublevskaya, B.I. Kupchinov, Wood-Polymer Structural Materials and Products, M.: Science and Technology, 1980, $278 \mathrm{p}$.

[11] N.I. Chubov, Metalized wood, Voronezh, Publishing House of Voronezh University, 1975, 133p.

[12] Thermal dissociation of organometallic compounds. Collection of research papers. M.: GNIICHTEOS, 1987, 192 p.

[13] A.I. Anuchin, T.K. Kasatkina, V.E. Miloshenko, Investigation of thermophysical properties of modified wood - Material of XV AllRussian scientific conference of students - physicists and young scientists of VNKSF. Kemerovo-Tomsk, 2009, pp. 299-300.

[14] V.G. Rakhmanov, A.V. Storozhenko, A.A. Walesky, A.V. Grebennikov "Method of modification of wood," Patent of the Russian Federation 2339505, 2008, Bulletin №1. 